\title{
On the Economic Importance of 'Nitragin.'
}

\author{
BY
}

\author{
MARIA DAWSON, D.Sc. (Lond. and Wales),
}

Late I85I Exhibition Science Research Scholar.

T $\mathrm{N}$ connexion with the comparatively recent rise of Agri1 culture as a practical science, there is perhaps no more important question than the supply of an adequate quantity of suitable nitrogenous food to plants, from which has arisen the study of the part played by the innumerable microorganisms of the soil and air in the regulation of this supply, both quantitatively and qualitatively.

The special interest of the Leguminosae in this connexion has been recognized ever since the classical researches of Boussingault, and from that time there has been an unbroken series of investigations-in particular those of Lawes, Gilbert, and Pugh in England and Hellriegel and Wilfarth in Germanyupon the phenomena involved in the increased nitrogen content of the soil, found to be a constant result of the cultivation of a Leguminous crop. The first important stage towards the explanation of these phenomena was reached by the determination that this increase in nitrogen was directly correlated with the presence upon the roots of the Leguminous plants of nodules, which owed their formation to the action of parasitic micro-organisms present in the soil. Beyerinck's discovery that the organisms were capable of growth on nutrient media, outside the plant, and that they could be obtained direct from the culture-soils, led to very

[Annals of Botany, Vol. XV. No. LIX. September, I90I.] 
many experiments upon plants in soils inoculated with artificial cultures of the organisms or with decoctions of soils in which the plant in question had been already cultivated. Such work as this led to the introduction by Nobbe and Hiltner of the substance 'Nitragin,' i.e. pure cultures of the nodule-organisms derived from different Leguminous plants, on a commercial scale for use in practical agriculture.

Although so much work has been done upon the relation existing between the presence or absence of Leguminous nodules and the proportion of nitrogenous material found in the culture-soils, but few workers have used the pure culture 'Nitragin' in exact experiments of this character, and so far as I am aware, in all cases, in which this material has been used, the conditions of the experiment have been very uncertain, owing chiefly to non-sterilized soils only being employed as culture media. Though not wishing to undervalue such experiments, I may point out that with such very complex conditions, it is impossible to fix upon any one variable condition as the certain cause of any observed effect produced in the crops, and indeed recent work upon this subject has tended to prove more and more clearly that not only is this problem of modern agriculture one of special difficulty, but that we can only hope to come to an adequate explanation of the facts involved by bringing to bear upon them evidence derived from the study of many apparently side issues.

Since 'Nitragin' was intended for use on a commercial scale and on any kind of soil, it seemed advisable that careful test experiments should be undertaken in a large number of different districts, and it was in order to furnish one such set of experiments that the work, to be briefly described in this paper, was undertaken during the summers of $1898-1900$ in the Cambridge University Botanical Laboratory and Gardens.

Throughout the work I had the privilege of the invaluable help and advice of Professor Marshall Ward, and I wish to take this opportunity of acknowledging my indebtedness to him. The results of some of this work have already been 
referred to in my earlier papers ${ }^{1}$ on the subject of the nodules of Leguminous plants, but further details were reserved in order to secure the advantage of a comparison of the experiments of three consecutive years, before any definite opinion was offered upon so complicated a subject.

The experiments referred to in this paper were of two distinct types :-

I. The plants were grown in media previously sterilized by heat [approximately $200^{\circ} \mathrm{C}$. for twenty-four hours], and throughout the experiment every precaution was taken to prevent any chance infection of the roots.

2. The plants were grown in the open air on unsterilized media.

In every case the same species was chosen for investigation, viz. Pisum sativum.

In the experiments on sterilized media the plants were grown in large pots containing respectively ordinary garden soil, a gravelly subsoil, pure silver-sand devoid of nitrogenous compounds, and a similar sand supplied with potassium nitrate. In each case one half of the pots were sown with seeds, previously inoculated with 'Nitragin,' whilst the other half contained control plants without inoculation. Before sowing, the seeds themselves were sterilized by immersion in a one per cent. solution of mercuric chloride for fifteen minutes ${ }^{2}$.

Experiments of this kind were carried out in three consecutive years, and in each year the crops were allowed to grow for about three months, that is until the pods were ripened, and throughout the time were watered with boiled distilled water only. At the end of this time the plants were carefully removed from the soil, and the roots thoroughly washed. A record was then made of the number of plants bearing nodules, the number of nodules formed and the dry

1 Phil. Trans. Roy. Soc., 1899 and 1900.

2 The use of this re-agent for cleansing the seeds was justified by the results of a preliminary experiment in which I found that 15 minutes' treatment with a one per cent. solution of mercuric chloride was without injurious effect on pea seeds, though a longer application killed the embryo. 
weight of the crops obtained. During the course of these experiments over 800 plants have been under investigation in this manner.

With regard to the relative weights of the crops the results showed that on ordinary garden soil, on sand, and on sand manured with nitrate, inoculation with 'Nitragin' is accompanied by a loss of weight in the crop, but that a small increase is secured on gravelly subsoil.

In sand-grown plants a considerable increase in the crop was produced by a supply of nitrates alone, but inoculation with 'Nitragin' in the presence of a sufficient supply of nitrogenous food, whether in the form of humus or of potassium nitrate, is not beneficial.

This set of experiments also showed clearly the extreme difficulty of securing sterile conditions in the culture-soils for a considerable period of time, and emphasized the fact of the undoubted ubiquity of the nodule-organisms in air and soils alike; for, in spite of the greatest care in all manipulations to prevent chance infection of the roots, nodules were frequently found on the roots of control-plants. It is scarcely possible that this was due to incomplete sterilization of the soils, for I have repeatedly grown peas and other Leguminous plants on media, treated in a similar manner for a period not exceeding six weeks, without any trace of infection. In addition, it should be pointed out that the nodules, when present on control-plants, were always fewer in number, smaller and more crowded together than those borne by plants inoculated with 'Nitragin.' Moreover the frequent occurrence of the fructification of Peziza confluens on these sterilized media shows how easily air-borne germs could be introduced. It would seem therefore that these noduleorganisms must be regarded as amongst the most ubiquitous of known organisms and, like those of putrefaction and fermentation, extremely difficult to remove with certainty for a considerable length of time. At one stage in the experiments it was observed that though no very appreciable difference could be detected between the vegetative organs 
of the plants with and without inoculation, the pods borne by inoculated plants were ripening more quickly than those borne by the plants without inoculation.

This observation lends support to the view recently put forward by Mattirolo ${ }^{1}$ that the root-nodules are organs for the elaboration of the albuminous materials required in the formation of the seeds. He found that if the formation of the fruit was prevented by the removal of all the young flower-buds, the contents of the nodules were not absorbed by the plants; whilst on the contrary the plants producing a normal quantity of fruit bore nodules which were completely emptied of their reserve stores of albuminous substances.

In the experiments on unsterilized media the plants were arranged-

I. In a parallel series of three sets of crops, grown in the summer of 1899 , upon ordinary garden-soils and a gravelly subsoil with and without inoculation with 'Nitragin ' and with and without an additional supply of nitrogenous food in the form of potassium nitrate.

2. In a series of crops grown in the summer of 1900 , on ordinary garden-soil, clay, peat and loam, in order to test the effect of inoculation with 'Nitragin' on media of different chemical composition.

As before the plants were allowed to grow until the pods were ripened, and records were then made of the numbers of infections and the dry weight of the crops.

These open-air experiments, which involved the cultivation of nearly 700 plants, led-like those conducted on sterilized media-to a very unfavourable conclusion as regards the practical value of 'Nitragin.' The nodule-organisms were found to be present in all types of soil, though they seem to be less abundant in clay and peat, and in these particular soils alone a large increase in the number of infections resulted from inoculation with 'Nitragin.'

${ }^{1}$ Mattirolo, 'Sulla Influenza che la Estirpazione dei Fiori exercita sui Tubercoli radicali delle Piante Leguminose,' 1900. 
As regards the relative weights of the crops, an increase as the result of inoculation was observed on the gravelly subsoil only, and even here the increase was but small ; on peat, clay, loam or ordinary garden-soil, on the contrary, inoculation with 'Nitragin' proved to be both useless and superfluous.

In the report of the work undertaken during the year I 897 , in the various experimental stations of Prussia ${ }^{1}$, accounts are given of the use of 'Nitragin' with different genera of the Leguminosae and on soils of different characters. In general the results show that the artificially cultivated organisms are either quite useless for infection or superfluous. On some soils, e.g. sandy heaths and moorland, it was found that inoculation with soils known to contain the organisms in question was more beneficial to the crops than the use of the pure culture, 'Nitragin.'

Frank $^{2}$, in a discussion of these results, suggests that the failure of 'Nitragin' as an agricultural fertilizer of Leguminous crops may be due to a change of properties having been induced in the organisms by artificial cultivation, which change has lessened their virulence, and consequent action within the host-plants. He concludes from these facts that a more suitable culture-medium should be adopted in order to keep the properties of the organisms unchanged. It is to be noticed, however, that this author has not suggested of what this new medium should consist. Nobbe and Hiltner ${ }^{3}$ hold the view that this loss of virulence is due to the same nutrient gelatine being used in each case, whatever the organism cultivated, e. g. Lupinus organisms on pea-extract gelatine.

They consider that the special adaptation of the 'bacteria' to each host is dependent upon the presence of different food materials within each host. According to these authors the value of nodules to the Leguminous plant is in direct propor-

1 Landwirthsch. Jahrb., I 898 , Band XXVIII.

' Frank, 'Die bisher erzielten Ergebnisse der Nitraginimpfung.' Landwirthsch. Versuchsst., 1899 .

${ }^{3}$ Nobbe and Hiltner, 'Wie lässt sich die Wirkung des Nitragins erhöhen?' Landwirthsch. Versuchsst., 1899. 
tion to the conversion of the 'bacteria' into bacteroids; unchanged 'bacteria' may be harmful rather than useful to the plant. They also state that if the plants are strengthened by the addition of small quantities of nitrogenous food to the soil, then nodules produced by artificially cultivated organisms are quite normal in their behaviour as nitrogen collectors. My own work has led me to an entirely opposite conclusion, viz.: that the more favourable the supply of nitrogenous food within the culture-media, the less likely is inoculation with 'Nitragin' to have any beneficial effect upon the crops.

In a general discussion of the kind of experiments referred to in this paper, it might justly be argued against the use of sterilized media that the conditions are here so altered that the results obtained cannot be regarded as comparable with those obtained under natural conditions.

On the other hand, the value of, and need for, experiments of this kind must be realized when we consider the unusual complexity. of the conditions existing in any ordinary soil. In media, thoroughly sterilized by heat, these conditions are to a large extent under control, and the disturbing action of soil-Bacteria removed, though even here, as we have seen, the difficulty of guarding against infection by air-borne germs is immense. In ordinary soils in the open-air, the conditions regulating the supply of nourishment and in particular of nitrogenous food to the plants are in the highest degree complicated, for along with the action of the nodule-organisms is involved the action of the various nitrifying and denitrifying Bacteria at work within the soil, besides frequent variations in the environment due to changes in the atmospheric conditions.

In this connexion reference should be made to Richter' ${ }^{1}$ investigations upon the effect of sterilization by heat, which causes considerable changes in the soil, in regard to its function as the main food-supply of plants-in particular, that the in-

1 Richter, ' ̈̇̉ber die Veränderungen welche der Boden durch das Sterilisieren erleidet.' Landwirthsch. Versuchsst., I 896. 
soluble nitrogenous compounds are converted into more easily assimilated forms. Such a change in the nature of the foodsupply would naturally lessen the plant's need of root-nodules as nitrogen-collectors. In ordinary soils, on the other hand, the processes of nitrification and denitrification, so continuously going on, produce frequent variations in the quantity and quality of the nitrogenous food available to higher plants ; so that in the struggle for existence it may well be a distinct advantage to the Leguminosae to have the power to draw upon additional supplies, provided through the agency of the rootnodules.

Further, the action of the host in the probable absorption from the nodules of the products of the activity of the symbiotic or parasitic organisms, doubtless in its turn aids in securing the continuance of their action upon the nitrogenous constituents of the soil or air. For it is quite conceivable that an accumulation of the products of their own metabolism within the nodules would in time result in the death of the organisms, or at least would entirely inhibit the exercise of their special metabolic functions. Such an accumulation of products in the artificial media of cultivation may perhaps be an important factor in the loss of virulence which seems to result from artificial cultivation, as compared with organisms derived direct from infected soils. From the strictly practical point of view, however, the problem is to determine the conditions under which a further supply of nodule-organismssuch as are now available-would be undoubtedly beneficial to the plants. I am inclined to think that a special study of these conditions is necessary for each type of Leguminous crop; Wollny ${ }^{1}$ has recently shown that on chalky soils yellow Lupins and Serradella do not react to infection of the soil with nodule-organisms, but that a considerable increase in their development is seen if they receive a supply of easily assimilable nitrogen compounds; and as another example I may repeat my former statement that for peas grown upon

1 Wollny, 'Versuche über die Wirkung des Nitragins.' Centralbl. für Bakt. u. Parasitenkunde, 189 \%. 
ordinary garden soil, peat, clay or loam inoculation with 'Nitragin' is useless and superfluous, whilst upon gravelly soils a small increase in crop results from its use.

These unfavourable results with 'Nitragin' lead to the conclusion that the explanation of the problem of the nutrition of Leguminous plants does not depend on the mere presence or absence of the nodule-organisms, but that their effect on the host is directly controlled by the conditions biological, physical and chemical, existing in the soil at any given time, so that it is from bacteriology and chemistry that we may expect to receive great help in the solution of this difficult problem of modern agriculture.

The Botanical Laboratory, Cambridge.

May, I90I. 


\section{$2 \mathrm{BHL}$ Biodiversity Heritage Library}

Dawson, Maria. 1901. "On the economic importance of 'nitragin'." Annals of botany 15, 511-519. https://doi.org/10.1093/oxfordjournals.aob.a088831.

View This Item Online: https://www.biodiversitylibrary.org/item/236929

DOI: https://doi.org/10.1093/oxfordjournals.aob.a088831

Permalink: https://www.biodiversitylibrary.org/partpdf/318635

\section{Holding Institution}

Smithsonian Libraries

\section{Sponsored by}

Biodiversity Heritage Library

\section{Copyright \& Reuse}

Copyright Status: Not in copyright. The BHL knows of no copyright restrictions on this item.

This document was created from content at the Biodiversity Heritage Library, the world's largest open access digital library for biodiversity literature and archives. Visit BHL at https://www.biodiversitylibrary.org. 